\title{
Kimmel Cancer Center
}

National Cancer Institute

\section{Source}

National Cancer Institute. Kimmel Cancer Center. NCI Thesaurus. Code C39440.

The mission of the Kimmel Cancer Center is to make transformational discoveries of the cellular and molecular biology of the malignant process and the individual's and society's response to it; effectively translate the latest research discoveries and clinical trials to provide the highest quality of care to all patients including those of diverse ethnic and racial populations; and provide expert and humanitarian care to cancer patients, their families, and those at risk. It received its $\mathrm{NCl}$ designation in 1996. 